\title{
Mental Health and Cross-Cultural Adaptation of Chinese International College Students in a Thai University
}

\author{
Pengfei Chen ${ }^{1}$, Xiang You ${ }^{1} \&$ Dui Chen ${ }^{1}$ \\ ${ }^{1}$ CHINA-ASEAN International College, Dhurakij Pundit University, Thailand \\ Correspondence: Xiang You, CHINA-ASEAN International College, Dhurakij Pundit University, Bangkok., 10210, \\ Thailand.
}

Received: July 24, 2018

doi:10.5430/ijhe.v7n4p133
Accepted: August 14, 2018

Online Published: August 15, 2018

URL: https://doi.org/10.5430/ijhe.v7n4p133

\begin{abstract}
Thai Immigration Department shows the total number of Chinese nationals residing in Thailand at 91,272 in 2015, however, academic studies reveal the figure to be as high as 350,000-400,000 in the past decade. In terms of the huge population, except economic benefit to Thailand and more cross-cultural settings in the campus, there is a critical issue requiring urgent attention. Colleges cannot guarantee high-quality learning and consequently cannot attain their mission, accomplish their goals, or serve their valuable social, economic and public objectives without engaging in the mental and behavioral health matters of their students. Accordingly, this study aimed to examine Chinese international students' mental health and cross-cultural adaptation to study abroad in a university at Bangkok and investigate whether or not two factors were related to one another. A survey was applied for this investigation. The participants were 900 Chinese international students at a Thai university. The research discovered that different levels of college degrees and length of residence in Thailand were two main factors to influence mental health and cross-cultural adaptation. Incoming students and graduates specifically has a potential problem in cross-cultural adaptation.
\end{abstract}

Keywords: Chinese international students, study abroad in a Thai university, mental health, cross-cultural adaptation

\section{Introduction}

In Southeast Asia, Thailand is the third most popular country to study for a substantial number of international college students after Malaysia and Singapore. According to the UNESCO Institute for Statistics, the number of international college students in Thailand grew by entirely 979 percent between 1999 and 2012, from 1,882 to 20,393 students. Most international students are from Asian neighbor countries, with China being the biggest sending nation. Surveys of Chinese students present that besides academic attention, the friendly environment including people, infrastructure, and affordability is also attractive factors (Michael, 2018). Ministry of Education in Thailand shows that in 2011, there were 20,309 international students studying in Thailand. The majority was Chinese students around 8,444 (Jaroensubphayanont, 2015). And this population has increased dramatically 45 times higher in the last five years. Thai Immigration Department displays the total number of Chinese nationals residing in Thailand at 91,272 in 2015; however, academic studies reveal the figure to be as high as 350,000-400,000 in the past decade (Fernquest \& Wangkiat, 2016). Accordingly, the number of foreign Chinese students coming to Thailand to study is also increasing and reaching significant numbers.

Studying abroad gradually becomes a common experience for young adults while the transition from high school to university as a part of their life trajectories. However, successful adaptation of a new university and to a new country needs effort and flexibility. Additionally, international students meet challenges to cultural transition beyond the general life and academic stresses (Brisset, Safdar, Lewis, \& Sabatier, 2010). Many factors are showed to impact on the mental health and well-being of international students (McKenna, Robinson, Penman, \& Hills, 2017). In fact, international students confront problems such as language skills, social support, and financial capacity influence their academic outcome, health and well-being (Burns, 1991). They have three forms of loneliness including personal, by lost connection with families; social, by the failure of networks; and cultural, because of the requirement to adopt the culture and language of the host country (Sawir, Marginson, Deumert, Nyland, \& Ramia, 2008). Other factors include racism (Iwamoto \& Liu, 2010), discrimination (Junious \& Malecha, 2008), gaps in expectation between students and academics (Kingston \& Forland, 2008), and culture or transition shock (McLachian \& Justice, 2009). Chinese students have been identified that they are often the smallest adjusted group among international students 
because of their prominent levels of stress, neuroticism, and perceived cultural distance (Forbush \& Foucault-Welles, 2016; Galchenko \& van de Vijver, 2016; Hazen \& Alberts, 2006).

\subsection{International Student's Mental Health}

World Health Organisation (WHO) defines mental health as a statement of well-being in which the individual comprehends his or her own capabilities, can manage with the normal stresses of life, is able to work effectively and productively, and can contribute to his or her community. Mental health includes the emotional flexibility that empowers us to enjoy life and to subsist pain, disappointment and sadness, and a fundamental belief in our own, and others' self-esteem and worth. It also allows us to participate effectively in and contribute to society or our community (Universities UK, 2015). International students are from diverse cultural, ethnic and religious backgrounds. When considering their mental health, it is crucial to realize the supplementary challenges in which they face in changing to living and studying abroad. They must take a major development of adjustment to a new academic and cultural environment. They are difficult to visit their home countries regularly. Academic achievement may be abridged by insufficient language skills. International students usually have high hopes of success and can convert to very anxieties if their academic performance drops short of their prospects and the hopes of their family who often provides financial support (Mccabe, 2005; Royal College of Psychiatrists, 2016).

Mental health issues are health situations including changes in emotion, behavior, or thinking (or a mixture of these). Mental health issues connect with distress and/or problems operation in work, social or family activities (Parekh, 2015). Mental health issues resulting from organic, genetic, psychological or behavioral factors (or composites of these) that happens in an individual and is not comprehended or anticipated as part of normal development or culture - can be serious or lasting and may belong to the definition of a 'disability' confined in the Equality Act 2010. It is crucial for institutions to take in mind, however, that not all mental health difficulties will form a 'disability' under the Equality Act (Universities UK, 2015).

\subsection{Cross-Cultural Adaptation}

The outcome of investigating acculturation is the adaptation, which has been stressed in some research in the cross-cultural literature (Brisset, Safdar, Lewis, \& Sabatier, 2010). Researchers of acculturation have distinguished two dimensions of cross-cultural adaptation, which are sociocultural (emotional/affective) adaptation and psychological (behavioral) adaptation. Psychological adaptation refers to stress and coping model, cultural identity, subjective well-being or satisfaction with transitions in a new cultural environment. And sociocultural adaptation refers to social learning paradigm and competence of managing daily life and social interactions in a new cultural setting (Ward \& Kennedy, 1993).

Psychological adaptation and sociocultural adaptation are correlated with one another but conceptually and empirically distinct (Berry, 1997), since they are predicted by various factors. Psychological adaptation is predicted by personality variables, events of life-changing and factors of social support. Sociocultural adaptation is predicted by the cultural distance between home and host countries, cultural identity, cultural knowledge and competence, linguistic skill, and contact with host nationals (Ward \& Kennedy, 1994).

\subsection{International Students' Mental Health and Cross-Cultural Adaptation}

International students are at higher risk of suffering from depressive symptoms because of issues interacting with the host culture and adapting to a new daily life (Spencer-Oatey \& Xiong, 2006). Stressful encounters include differences in communication and culture, homesickness, loneliness, stereotyping and prejudice, limited social skills, and academic burden. Facing one or more of these problems will cause negative psychological results, such as depressive symptoms (Jung, Hecht, \& Wadsworth, 2007). Few studies abroad specialists, specifically those who work directly with students, have been unable to cope with matters initiated by students managing problems such as depression, anxiety, addiction, eating disorders, obsessive compulsiveness, schizophrenia, post-traumatic stress disorder, agoraphobia, and others. International student mental health and mental health issues alarms have important inferences in the environment of an overseas experience (Mccabe, 2005).

The approximated occurrence of any depressive or anxiety disorder was $15.6 \%$ for bachelor students and $13.0 \%$ for master and doctoral students in an internet-based survey in the USA (Eisenberg et al., 2007). A study in Lebanon claimed that the frequency of depression in medical students was as high as 28\% (Mehanna, 2005). Another research from Pakistan showed that $19.5 \%$ of depression and $43.7 \%$ of anxiety occurred in female medical students (Rab, Mamdou, \& Nasir, 2008). An online survey was used to investigate the occurrence and correlates of self-harm in bachelor, master and doctoral students attending a public university in America: 7\% of students reported some having self-injury in the earlier 4 weeks. Both men and women had similar rates. Self-injury was associated with 
depressive and anxiety symptoms, cigarette smoking, and suicidal thoughts, in the case of men, growing up in a low socioeconomic status household (Gollust, Eisenberg, \& Golberstein, 2008).

International college students particularly experience unique life challenges that can put them at an even higher risk for generating symptoms of depression (Yakunina, Weigold, Weigold, Hercegovac, \& Elsayed, 2013). They underlined a cross-cultural phase of loneliness and recognized the notion of cultural loneliness as central (Sawir, Marginson, Deumert, Nyland, \& Ramia, 2008). These encounters involve language barrier, lack of understanding of a culture, and difficulty with looking for academic help (Olivas \& Li, 2006). Although international students are fluent in the host country's language, they may find it difficult to adjust to the diverse types of instruction, for instance, that is rote memorization vs. discussion-based learning (Forbush \& Foucault-Welles, 2016). Thailand has seen a very recent increase in Chinese students, which presents a largely substitute and vulnerable population (Douce $\&$ Keeling, 2010).

\subsection{Hypotheses}

The central aim of this research was to investigate Chinese international students' mental health and cross-cultural adaptation to study abroad in a Thai university in Bangkok. The relationship between Chinese international students' college life adaptation, mental health issues, and cross-cultural adaptation was examined. Specifically, the following hypotheses were formulated.

Hypothesis 1. Chinese international students' mental health and cross-cultural adaptation are significantly related to one another.

Hypothesis 2. There is no difference in the effects of mental health and cross-cultural adaptation among both genders of Chinese international students.

Hypothesis 3. There is a difference in the effects of mental health and cross-cultural adaptation among educational degrees of Chinese international students.

Hypothesis 4. There is a difference in the effects of mental health and cross-cultural adaptation among different residence length in Thailand of Chinese international students.

\section{Method}

\subsection{Participants and Procedure}

A total of 1300 participants took part in this research. All of them were Chinese citizens, who were 18 years or older, and had been studying at a university in Bangkok, Thailand for less than one year to three years. The study applied a purposive sample to investigate this population. A Thai university had a substantial number of Chinese international students around 3,000 taking a bachelor, master or Ph.D. degree. The Chinese international students were informed about the intent of the research and the voluntary nature of participation in the study. They were also informed that they could opt out at any time during the online survey and all data collected in this research would be anonymous to protect their identity.

After operating the online survey for a month, a total of 1080 surveys were returned (accounting for 83.08\% response rate). However, further data inspection showed surveys with high missing values, which were removed, producing a total of 900 valid responses. 395 of the 900 respondents $(43.9 \%)$ were female, and 505 were male (56.1\%). All students were studying on either an undergraduate $(n=731,81.2 \%)$ or a graduate $(n=169,18.2 \%)$ degree. 110 of 900 students stayed in Thailand less than 6 months (12.2\%), 380 were around 6 months to a year (42.2\%), 236 were about 1 year and 2 years $(26.2 \%), 128$ were 2 to 3 years $(14.2 \%)$, and 46 were more than 3 years $(5.2 \%) .900$ respondents were from 8 different fields of study including 28 students were in MBA (3.1\%), 57 were in MBA of finance (6.3\%), 407 were in finance and accounting (45.2\%), 66 were in travel management (7.3\%), 236 were in international business $(26.2 \%), 73$ were in education management $(8.1 \%), 2$ were in media and art $(0.2 \%)$, and 31 were in art and design (3.4\%).

\subsection{Measures}

The survey was written in Chinese. The validated Chinese version included demographic information of the measure of mental health including college life adaptation and mental health issues were adopted. The measure of cross-cultural was translated from English items into Chinese with back-translation to confirm theoretical equivalence. 


\subsubsection{College Students' Mental Health}

The "college students' adaptation and health scale" was applied (Xiu \& Lin, 2010). In terms of diathesis stress models, the scale includes two main parts including 'life adaptation' with 8 factors having 30 items to measure students' adaption in daily life and 'mental health issues with 3 factors including 32 items to assess students' ill physiological and psychological condition. The 8 factors of 'college life stress' are time management, career planning, learning, family, interpersonal relationship, sentiment, emotion, and self-worth. The other 3 factors of 'mental health issues' are self-hurt, depression, and psychological problem. The design of questionnaires was 5-point Likert-scale from $1=$ never happened to $5=$ always happened. The mean score is 3 or higher than 3 , indicating students probably having problem with life adaptation or in no good condition of mental health issues. The alpha coefficient for two parts was .947, which had relatively high internal consistency. LISREL was applied to evaluate validity. P value of Chi-square test was .000 ( $\mathrm{p}<.05$ ); GFI was .84; AGFI was .76; SRMR was .068; RMSEA was 0.15; NFI, NNFI, CFI, IFI, RFI were higher than 0.9; NFI, NNFI, CFI, IFI, RFI were also greater than .90. These represented the very good fit of the data.

\subsubsection{Cross-Cultural Adaptation}

An instrument of Difficulty of Sociocultural Adjustment (DSA) to assess cross-cultural adaptation on the basis of Sociocultural Adaptation Scale (SCAS) was validated. The scale contained three subscales including 'university academic', 'contact with people', and 'daily life'. The reliability alphas of the instrument were ranged from 0.71 to 0.91 ( $M=0.91)$ (Xiong, 2005). In this study, only the measures of university academic and daily life were adopted and modified. University academic was assessed with 11 items. And daily life was evaluated with 15 items. The design of questionnaires was 5-point Likert-scale from $1=$ strongly disagree to $5=$ strongly agree. In addition, the scale of intercultural communication apprehension was developed based on the Personal Report of Intercultural Communication Apprehension (PRICA) with 14 items, and 5-point Likert scale was used for the answers of the participants from $1=$ Strongly disagree to $5=$ Strongly agree. Cronbach's alpha value of the scale was 0.817 , presenting reliable at an acceptable level (Seyitoğlu, Güven, \& Kocabulut, 2015). This study adopted the PRICA and modified instead of contact with people in the DSA. The mean score is 3 or higher than 3 , indicating students potentially able to adjust cross-cultural life.

\section{Results}

\subsection{Means, Standard Deviation, Inter-Correlations and Scale Reliabilities}

Table 1 shows the mean scores and standard deviations for life adaptation (2.03 and 0.69 respectively), for mental health issues (1.37 and 0.55 respectively), for cross-cultural adaptation (2.57 and 0.68 respectively). The result presents significant positive correlations among the study variables $(\mathrm{p}<0.01)$. The results also demonstrate the reliability of items as shown by the Cronbach's alpha (ranging from 0.938 to 0.958 ). Hypothesis 1 was supported as Chinese international students' life adaptation, mental health issues, and cross-cultural adaptation had a significant correlation, but they had low levels of correlation.

Table 1. Means, standard deviations, inter-correlations and scale reliabilities ( $\mathrm{N}=900)$.

\begin{tabular}{llllll}
\hline Variables & Mean & SD & 1 & 2 & 3 \\
\hline 1. Life adaptation & 2.03 & 0.69 & $(0.950)$ & & \\
$\begin{array}{l}\text { 2. Mental health issues } \\
\text { 3. Cross-cultural }\end{array}$ & 1.37 & 0.55 & $0.643^{* *}$ & $(0.958)$ & \\
adaptation & 2.57 & 0.68 & $0.371^{* *}$ & $0.200^{* *}$ & $(0.938)$ \\
\hline Note. $*^{*} \mathrm{p}<0.01$ & & & & &
\end{tabular}

\subsection{Confirmatory Factor Analysis}

Confirmatory factor analyses were applied to examine the distinctiveness of the study variables. AMOS IBM version 12 was used to assess model fit as presenting the chi square test, the comparative fit index (CFI), the Tucker-Lewis index (TLI) and the root mean square error of approximation (RMSEA). Values for the CFI and TLI that range from 0 to 1.00 with values closer to 1.00 are revealing of a good fit (Hu \& Bentler, 1998; Kline, 1998) And an RMSEA value of 0.08 or less shows an acceptable fit (Kline, 1998).

The first model with life adaptation was tasted. The result showed a good fit between the data and the model: $\mathrm{x} / \mathrm{df}=$ 3.69; $\mathrm{CFI}=0.92 ; \mathrm{TLI}=0.94$; and RMSEA $=0.06$. The second model had acceptable indices. The fit indices for the 
model tested with mental health issues were: $\mathrm{x} 2 / \mathrm{df}=4.69 ; \mathrm{CFI}=0.91$; $\mathrm{TLI}=0.94$; and RMSEA $=0.06$. The third model had adequate indices. The fit indices for the model tested with cross-cultural adaptation were: $\mathrm{x} 2 / \mathrm{df}=7.71$; $\mathrm{CFI}=0.90 ; \mathrm{TLI}=0.9 ;$ and $\mathrm{RMSEA}=0.08$.

\subsection{Analysis of Demographic Effects}

Hypothesis 2 was supported as no difference in the effects of life adaptation $(\mathrm{t}=1.88, \mathrm{p}>.05)$, mental health issues $(\mathrm{t}=1.72, \mathrm{p}>.05)$, and cross-cultural adaptation $(\mathrm{t}=1.53, \mathrm{p}>.05)$ among both genders of Chinese international students. This indicates that both male and female Chinese international college students had a comparable situation in mental health and adapting cross-cultural life and environment.

Consistent with Hypothesis 3 was supported. A one-way ANOVA was conducted to compare the effect of mental health and cross-cultural adaptation for educational levels in freshman, sophomore, junior, senior and graduates of Chinese international students as shown in Table 2. There was a significant effect of life adaptation in educational levels at the $\mathrm{p}<.05$ level for the 5 conditions $[\mathrm{F}(4,895)=7.18, \mathrm{p}<.001]$. Post hoc comparisons applying the Scheffe's method showed that the mean score for sophomores $(M=2.18, S D=0.64)$ and juniors $(M=2.20, S D=0.76)$ were significantly different than freshmen $(M=1.95, S D=0.71)$, seniors $(M=1.92, S D=0.66)$, and graduates $(M=2.18$, $\mathrm{SD}=0.64)$ respectively, indicating that sophomores and juniors had significant worse life adaptation than freshmen, seniors, and graduates individually.

Also, there was a significant effect of mental health issues in educational levels $[\mathrm{F}(4,895)=6.95, \mathrm{p}<.001]$. The result of post hoc indicated that the mean score for sophomores $(\mathrm{M}=1.45, \mathrm{SD}=0.57)$ and juniors $(\mathrm{M}=1.55, \mathrm{SD}=$ $0.69)$ were significantly different than freshmen $(\mathrm{M}=1.28, \mathrm{SD}=0.51)$, seniors $(\mathrm{M}=1.29$, $\mathrm{SD}=0.49)$, and graduates $(\mathrm{M}=1.94, \mathrm{SD}=0.65)$ individually. It presented that sophomores and juniors had a significantly higher level of mental health issues than freshmen, seniors, and graduates respectively. However, the mean of sophomores and juniors were still low, indicating that they did not have a fundamental problem in mental health issues.

In addition, cross-cultural adaptation had a significant effect in educational levels $[\mathrm{F}(4,895)=5.10, \mathrm{p}<.001]$. The result of the post hoc showed that the mean score for sophomores $(M=2.70, \mathrm{SD}=0.61)$ was significantly different than freshmen $(\mathrm{M}=2.49, \mathrm{SD}=0.76)$ and graduates $(\mathrm{M}=2.47, \mathrm{SD}=0.64)$ respectively, indicating that sophomores could adjust cross-cultural environment significantly better than freshmen and graduates.

Table 2. Life adaptation, mental health issues, and cross-cultural adaptation in different educational levels

\begin{tabular}{|c|c|c|c|c|c|}
\hline \multirow{2}{*}{ Variables } & \multirow{2}{*}{ Educational levels } & \multirow{2}{*}{$\mathrm{N}$} & \multicolumn{2}{|r|}{ ANOVA } & \multirow{2}{*}{ Post hoc } \\
\hline & & & Mean SD & $S S \quad D F \quad M S$ & \\
\hline \multirow{5}{*}{ Life adaptation } & (1) & 246 & 1.950 .71 Between groups & $13.43 \quad 43.367 .18 * * *$ & $2,3>1$ \\
\hline & (2) & 219 & 2.180 .64 Within groups & 418.308950 .47 & $2,3>4$ \\
\hline & (3) & 119 & $2.200 .76 \quad$ Total & 431.73899 & $2,3>5$ \\
\hline & (4) & 147 & 1.920 .66 & & \\
\hline & (5) & 169 & 1.940 .65 & & \\
\hline \multirow{5}{*}{ Mental health issues } & (1) & 246 & 1.280 .51 Between groups & $42.026 .95 * * *$ & $2,3>1$ \\
\hline & (2) & 219 & 1.450 .57 Within groups & 260.498950 .29 & $3>4$ \\
\hline & (3) & 119 & $1.550 .69 \quad$ Total & 268.58899 & \\
\hline & (4) & 147 & 1.290 .49 & & \\
\hline & (5) & 169 & 1.360 .47 & & \\
\hline \multirow{5}{*}{ cross-cultural adaptation } & (1) & 246 & 2.490 .76 Between groups & $9.26 \quad 42.325 .10 * * *$ & $2>1$ \\
\hline & (2) & 219 & 2.700 .61 Within groups & 406.618950 .45 & $2>5$ \\
\hline & (3) & 119 & $2.700 .62 \quad$ Total & 415.87899 & \\
\hline & (4) & 147 & 2.500 .69 & & \\
\hline & $(5)$ & 169 & 2.470 .64 & & \\
\hline
\end{tabular}

Note. (1)freshman,(2)sophomore,(3)junior,(4)senior,(5)graduate; ***p<.001

Hypothesis 4 was supported. One-way ANOVA was used to analyze the effect of mental health and cross-cultural adaptation among different residence length in Thailand of Chinese international students as shown in Table 3. There was a significant effect of life adaptation $(\mathrm{F}=7.65, \mathrm{p}<.001)$ and mental health issues $(\mathrm{F}=7.65, \mathrm{p}<.001)$ in different length of staying in Thailand at the $\mathrm{p}<.05$ level for the 5 conditions including less than 6 months, 6 months and above to 1 year, 1 year and above to 2 years, 2 years and above to 3 years, and 3 years and above. Post hoc comparisons employing the Scheffe's method in life adaptation presented that the mean score for 1 year and above to 2 years $(\mathrm{M}=$ $2.16, \mathrm{SD}=0.65)$ and 2 years and above to 3 years $(\mathrm{M}=2.20, \mathrm{SD}=0.73)$ were significantly different than less than 6 
months $(\mathrm{M}=1.83, \mathrm{SD}=0.64)$ and 6 months and above to 1 year $(\mathrm{M}=1.95, \mathrm{SD}=0.70)$, indicating that the students who stayed in Thailand longer had a significantly worse life adaptation. However, the mean score was lower than 3. It meant the students in the acceptable condition of life adaptation.

Table 3. Life adaptation, mental health issues, and cross-cultural adaptation among different residence length in Thailand of Chinese international students

\begin{tabular}{|c|c|c|c|c|c|c|c|}
\hline \multirow{2}{*}{ Variables } & \multirow{2}{*}{ Educational levels } & \multirow{2}{*}{$\mathrm{N}$} & \multirow{2}{*}{ Mean SD } & \multicolumn{3}{|c|}{ ANOVA } & \multirow{2}{*}{$\begin{array}{l}\text { Post } \\
\text { hoc }\end{array}$} \\
\hline & & & & $S V$ & $S S \quad D F \quad M S$ & $F$ & \\
\hline \multirow{5}{*}{ Life adaptation } & (1) & 236 & $2.160 .65 \mathrm{I}$ & Between groups & $14.27 \quad 43.57$ & $7.65^{* * *}$ & $3,4>1,2$ \\
\hline & (2) & 46 & 2.050 .69 & Within groups & 417.468950 .47 & & \\
\hline & (3) & 110 & 1.830 .64 & Total & 431.73899 & & \\
\hline & (4) & 380 & 1.950 .70 & & & & \\
\hline & $(5)$ & 128 & 2.200 .73 & & & & \\
\hline \multirow{5}{*}{ Mental health issues } & (1) & 236 & $1.450 .56 \mathrm{I}$ & Between groups & $\begin{array}{lll}6.56 & 4 & 1.64\end{array}$ & $5.60 * * *$ & $3,4>1,2$ \\
\hline & (2) & 46 & 1.440 .65 & Within groups & 262.038950 .29 & & \\
\hline & (3) & 110 & 1.250 .47 & Total & 268.58899 & & \\
\hline & (4) & 380 & $\begin{array}{lll}1.31 & 0.50\end{array}$ & & & & \\
\hline & (5) & 128 & 1.490 .62 & & & & \\
\hline \multirow{5}{*}{ cross-cultural adaptation } & (1) & 236 & $2.630 .59 \mathrm{I}$ & Between groups & $4.60 \quad 41.15$ & $2.50 *$ & $3,4>1$ \\
\hline & (2) & 46 & 2.500 .68 & Within groups & 411.278950 .46 & & \\
\hline & (3) & 110 & 2.430 .70 & Total & 415.87899 & & \\
\hline & (4) & 380 & 2.540 .73 & & & & \\
\hline & (5) & 128 & 2.660 .64 & & & & \\
\hline
\end{tabular}

Note. (1)less than 6 months,(2)6 months and above to 1 year,(3)1 year and above to 2 years,(4)2 years and above to 3 years, (5) 3 years and above; $* \mathrm{P}<.05, * * * \mathrm{p}<.001$

Also, the breakdown of the post hoc comparisons in mental health issues showed that the mean score for 1 year and above to 2 years $(\mathrm{M}=1.45, \mathrm{SD}=0.56)$ and 2 years and above to 3 years $(\mathrm{M}=1.49, \mathrm{SD}=0.62)$ were significantly different than less than 6 months $(\mathrm{M}=1.25, \mathrm{SD}=0.47)$ and 6 months and above to 1 year $(\mathrm{M}=1.31, \mathrm{SD}=0.50)$, presenting that the longer the students staying in Thailand had a significant problem of mental health issues. However, the mean scores were lower than 2, which indicated that the situation of mental health issues was still in normal condition.

Additionally, cross-cultural adaptation had a significant effect on different residence length in Thailand of the students $(\mathrm{F}=2.50, \mathrm{p}<.05)$. The result of the post hoc presented that the mean score for 1 year and above to 2 years $(\mathrm{M}$ $=2.63, \mathrm{SD}=0.59)$ and 2 years and above to 3 years $(\mathrm{M}=2.66, \mathrm{SD}=0.64)$ were significantly different than less than 6 months $(\mathrm{M}=12.43, \mathrm{SD}=0.70)$, indicating that the students staying in Thailand longer more than 1 year could adapt cross-cultural settings significant better than new students.

\section{Discussion}

This study aimed to examine Chinese international students' mental health and cross-cultural adaptation to study abroad in a Thai university in Bangkok and investigate whether or not two factors related to one another. Mental health has two dimensions including life adaptation and mental health issues. The results provide partial support. As predicted, mental health and cross-cultural adaptation had a significant correlation. Previous studies showed that psychological adaptation and social-cultural factor having a closed inter-relation (Brisset, Safdar, Lewis, \& Sabatier, 2010; Ng, Wang, \& Chan, 2017; Presbitero, 2016). However, the current study shows that mental health and cross-cultural adaptation had a low level of association. The finding is somehow little different with pieces of literature. It probably can be assumed that the university in the context of numerous Chinese international students in this study affected the reduction of psychological problem in the process of cross-cultural settings.

In terms of demographic factors, the first major finding was that both male and female Chinese international college students had no significant difference in mental health and cross-cultural adaptation. The previous study illustrated both men and women of international students had similar rates in mental health issues (Gollust, Eisenberg, \& Golberstein, 2008). Some researchers demonstrated that adjustment toward the culture is primarily dependent on gender; for instances, females showed to be more satisfactory toward the Dutch culture than males. Nevertheless, this is contrary to the results which found no sex variances in the change of Moroccan people in the Netherlands (Ouarasse \& Vijver, 2005). Our findings expand upon this to show that no gender differences in mental health issues 
and cross-cultural adaptation.

The second major finding was that different educational degrees of Chinese international students had a significant difference in mental health and cross-cultural adaptation. The previous research showed that both undergraduates and graduates had a problem with mental health (American College Health Association, 2015). Also, bachelor students and graduate students had a statistical difference in mental health issues (Eisenberg et al., 2007). Our findings develop based on this to illustrate that different educational levels of Chinese international student had a significant effect in mental health and cross-cultural adaptation, especially sophomores and juniors had a significantly higher level of mental health issues than freshmen, seniors, and graduates correspondingly. However, the mean scores for educational levels in mental health were low, presenting that they did not have an essential problem on mental health issues. In contrast, the mean score in cross-cultural adaptation was lower than 3, indicating that the students had a somewhat problem in cross-cultural settings, especially freshman and graduates showing significant potential difficult than sophomores.

The third major finding showed the length of stay in Thailand of Chinese international students had a significant difference in mental health and cross-cultural adaptation. When the students stayed in Thailand longer, they somewhat got a problem with mental health issues. However, they got a better cross-cultural adaptation. The result is consistent with previous studies that showed longer residence was associated with significantly decreased levels of acculturative distress (Wilton \& Constantine, 2003; Ying, 2005). Nevertheless, other studies showed no correlation between length of host-country residence and acculturative stress (Ye, 2005).

\subsection{Implication}

The study provided a contribution of investigating the condition of mental health and cross-cultural adaptation for Chinese international students in a Thai university. In terms of findings, the research found out that different educational degrees and length of residence in Thailand were two main factors to influence mental health and cross-cultural adaptation. Incoming students and graduates specifically has a potential problem in cross-cultural adaptation. It has been suggested that sojourning students would experience some acculturative stressors, for example, language problem, discrimination, loneliness, homesickness, financial issues, daily living tasks, and academic problems due to the new educational settings (Wei, Heppner, Mallen, Liao, \& Wu, 2007). In addition, the longer the students stay in Thailand, the greater the chance of them to develop mental health problem. Some studies showed that increased time in the host-country influences acculturative stress in international students (Smith \& Khawaja, 2011).

Although this study provides important insights into examining mental health and cross-cultural adaptation of Chinese international students in a Thai university, it is not without limitations. First, the research only conducted sampling in one university. The current finding may not generalize to other samples of Chinese international students. Further studies are needed to assess the generalizability of our findings to other samples of Chinese international students in Thailand. Second, this study only used an overall measure of correlation and demographic factors in mental health and cross-cultural adaptation but did not examine risk factors that cause these problems. Future work is suggested to investigate what risk factors may moderate the associations between mental health and cross-cultural adaption and examine causation between the variables.

\section{Conclusion}

As a concluding remark, the present investigation examined the circumstances of mental health and cross-cultural adaptation for Chinese international students in a Thai university. The research found that different levels of college degrees and length of residence in Thailand were two main factors affecting mental health and cross-cultural adaptation. When the students stayed in Thailand longer, their condition in mental health was getting somewhat worse. Incoming students and graduates specifically has a potential problem in cross-cultural adaptation. However, the research only conducted sampling in one university. Further studies are needed to assess the generalizability of our findings to other samples of Chinese international students in Thailand, examine what risk factors may moderate the associations between mental health and cross-cultural adaption, and investigate causation between the variables.

\section{Acknowledgements}

The research is the grant from Dhurakij Pundit University, Chinese-ASEAN International College (CAIC). The authors thank some teachers in CAIC for helping to collect data used in this study.

\section{References}

American College Health Association. (2015). American College Health Association-National College Health 
Assessment; Reference Group Executive Summary Spring 2015. Retrieved from http://www.acha-ncha.org/docs/ACHA-NCHA_Reference_Group_ExecutiveSummary_Spring2015.pdf.

Berry, J. W. (1997). Immigration, acculturation and adaptation. Applied Psychology, 46(1), 5-34. https://doi.org/10.1111/j.1464-0597.1997.tb01087.x

Brisset, C., Safdar, S., Lewis, J. R., \& Sabatier, C. (2010) Psychological and sociocultural adaptation of university students in France: The case of Vietnamese international students. International Journal of Intercultural Relations, 34, 413-26. https://doi.org/10.1016/j.ijintrel.2010.02.009

Burns, R. B. (1991). Study and stress among first year overseas students in an Australian university. High. Edu. Res. Dev, 10(1), 66-77. http://dx.doi.org/10.1080/0729436910100106

Douce, L. A., \& Keeling, R. P. (2014). A strategic primer on college student mental health. Washington, D.C.: American Council on Education.

Eisenberg, D., Gollust, S. E., Golberstein, E., \& Hefner, J. L. (2007). Prevalence and correlates of depression, anxiety, and suicidality among university students. American Journal of Orthopsychiatry, 77(4), 534-542. http://dx.doi.org/10.1037/0002-9432.77.4.534

Fernquest, J., \& Wangkiat, P. (2016). New wave of Chinese coming to live in Thailand. Bangkok Post. Retrieved from https://www.bangkokpost.com/learning/advanced/1093148/new-wave-of-chinese-coming-to-live-in-thailand.

Forbush, E., \& Foucault-Welles, B. (2016). Social media use and adaptation among Chinese students beginning to study in the United States. International Journal of Intercultural Relations, 50, 1-12. https://doi.org/10.1016/j.ijintrel.2015.10.007

Galchenko, I., \& van de Vijver, F. J. R. (2007). The role of perceived cultural distance in the acculturation of exchange students in Russia. International Journal of Intercultural Relations, 31(2), 181-197. http://dx.doi.org/10.1016/j.ijintrel.2006.03.4

Gollust, S. E., Eisenberg, D., \& Golberstein, E. (2008). Prevalence and correlates of self-injury among university students. Journal of American College Health, 56(5), 491-498. http://dx.doi.org/10.3200/JACH.56.5

Hazen, H. D., \& Alberts, H. C. (2006). Visitors or immigrants? International students in the United States. Population, Space and Place, 12(3), 201-216. https://doi.org/10.1002/psp.409

Hu, L. -T., \& Bentler, P. M. (1998). Fit indices in covariance structure modelling; sensitivity to under-parameterized model misspecification. Psychological Methods, 3(4), 424-453. http://dx.doi.org/10.1037/1082-989X.3.4.424

Iwamoto, D. K., \& Liu, W. M. (2010) The impact of racial identity, ethnic identity, Asian values, and race-related stress on Asian American and Asian international college students' psychological wellbeing. J. Couns. Psychol, 57(1). 79-91. https://doi.org/10.1037/a0017393

Jaroensubphayanont, N. (2014). The international student policy in Thailand and its implications on the 2015 ASEAN economic community. Southeast Asian studies in Asia from multidisciplinary perspective international conference. https://doi.org/10.13140/RG.2.1.2191.9447

Jung, E., Hecht, M. L., \& Wadsworth, B. C. (2007). The role of identity in international students' psychological well-being in the United States: A model of depression level, identity gaps, discrimination, and acculturation. International Journal of Intercultural Relations, 31(5), 605-624. https://doi.org/10.1016/j.ijintrel.2007.04.001

Junious, D. L, Malecha, A., Tart, K., \& Young, A. (2010). Stress and perceived faculty support among foreign-born $\begin{array}{lllll}\text { baccalaureate nursing students. J. Nurs. } & \text { Educ., } & \text { 49(5), }\end{array}$ http://dx.doi.org/10.3928/0148483420100217-02

Kingston, E., \& Forland, H. (2008). Bridging the gap in expectations between international students and academic staff. Journal of Studies in International Education, 12(2), 204-221.

Kline, R. B. (1998). Principles and practice of structural equation modeling. New York: Guilford Press.

Mccabe, L. (2005). Mental Health and Study Abroad: Responding to the Concern. Education abroad, 52-57. Retrieved from https://www.nafsa.org/_/File/_/InternationalEducator/EducationAbroadNovDec05.pdf.

McKenna, L., Robinson, E., Penman, J., \& Hills, D. (2017). Factors impacting on psychological wellbeing of international students in the health professions: A scoping review. International Journal of Intercultural Relations, 74, 85-94. https://doi.org/10.1016/j.ijnurstu.2017.06.007 
McLachian, D. A., \& Justice, J. A (2009). Grounded theory of international student well-being. J. Theory Construct Test, 13(1), 27-32.

Mehanna, Z., \& Richa, S. (2006). Prevalence of anxiety and depressive disorders in medical students: transversal study in medical students in the Saint-Joseph University of Beirut. Encephale, 32(6 Pt 1), 976-982. https://doi.org/10.1016/S0013-7006(06)76276-5

Michael, R. (2018). Education in Thailand. World Education News + Reviews. Retrieved from https://wenr.wes.org/2018/02/education-in-thailand-2

Ng T. K., Wang, K. W. C., \& Chan, W. (2017). Acculturation and cross-cultural adaptation: The moderating role of social support. International Journal of Intercultural Relations, 59, 19-30. https://doi.org/10.1016/j.ijintrel.2017.04.012

Olivas, M., \& Li, C. (2006). Understanding stressors for international students in higher education: What college counselors and personnel need to know. Journal of Instructional Psychology, 33(3), 217-222.

Ouarasse, O. A., \& Vijver, F. (2005). The role of demographic variables and acculturation attitudes in predicting sociocultural and psychological adaptation in Moroccans in the Netherlands. International Journal of Intercultural Relations, 29(3), 251-272. https://doi.org/10.1016/j.ijintrel.2005.06.005

Parekh, R., M.D. M.P.H. (2015, November). What is mental illness?. America Psychiatric Association. Retrieved from https://www.psychiatry.org/patients-families/what-is-mental-illness.

Presbitero, A. (2016). Culture shock and reverse culture shock: The moderating role of cultural intelligence in international students' adaptation. International Journal of Intercultural Relations, 53, 28-38. https://doi.org/10.1016/j.ijintrel.2016.05.004

Rab, F., Mamdou, R., \& Nasir, S. (2008). Rates of depression and anxiety among female medical students in Pakistan [English with Arabic and French abstracts]. Eastern Mediterranean Health Journal, 14, 127-133.

Royal College of Psychiatrists. (2016). Mental health of students in higher education. Retreived from http://www.rcpsych.ac.uk

Sawir, E., Marginson, S., Deumert, A., Nyland, C., \& Ramia, G. (2008). Loneliness and international students: an Australian study. Journal of Studies in International Education, 12(2), 148-180. https://doi.org/10.1177/1028315307299699

Seyitoğlu, F., Güven, A., Kocabulut, Ö. (2015). Effects of intercultural communication apprehension on satisfaction of foreign students. Proceeding of the First European Academic Research Conference on Global Business, Economics, Finance and Social Sciences (EAR15_Italy Conference) (pp. 1-12). Milan, Italy.

Smith, R. A., \& Khawaja, N. G. (2011). A review of the acculturation experiences of international students. International. Journal of Intercultural Relations, 35(6), 699-13. https://doi.org/10.1016/j.ijintrel.2011.08.004

Spencer-Oatey, H., \& Xiong, Z. (2006). Chinese students' psychological and sociocultural adjustments to Britain: An empirical study. Language, Culture and Curriculum, 19(1), 37-53. https://doi.org/10.1080/07908310608668753

Universities UK. (2015). Student mental wellbeing in higher education: Good practice guide. Retrieved from http://www.universitiesuk.ac.uk.

Ward, C., \& Kennedy, A. (1993). Psychological and socio-cultural adjustment during cross-cultural transitions: A comparison of secondary students overseas and at home. International Journal of Psychology, 28(2), 129-147. https://doi.org/10.1080/00207599308247181

Ward, C., \& Kennedy, A. (1994). Acculturation strategies, psychological adjustment and sociocultural competence during cross-cultural transitions. International Journal of Intercultural Relations, 18(3), 329-343. https://doi.org/10.1016/0147-1767(94)90036-1

Wei M, Heppner PP, Mallen MJ, Ku TY, Liao KYH, Wu TF. (2007). Acculturative stress, perfectionism, years in the United States, and depression among Chinese international students. Journal of Counseling Psychology, 54(4), 385-394. https://doi.org/10.1037/0022-0167.54.4.385

Wilton, L., \& Constantine, M. G. (2003). Length of residence, cultural adjustment difficulties, and psychological distress symptoms in Asian and Latin American international college students. Journal of College Counseling, 6(2), 177-186. https://doi.org/10.1002/j.2161-1882.2003.tb00238.x

Xiong, Z. N. (2005). Cross-cultural adaptation and academic performance: Overseas Chinese students on an 
international foundation course at a British university (unpublished dissertation). University of Luton, UK.

Xiu, H., \& Lin, X. (2010). Building National Chengchi University Students' adaption and health questionnaire. Taipei: National Chengchi University (NCCU). Retrieved from http://nccur.lib.nccu.edu.tw/bitstream/140.119/38755/3/\%E5\%9C\%8B\%E7\%AB\%8B\%E6\%94\%BF\%E6\%B2\% BB\%E5\%A4\%A7\%E5\%AD\%B8\%E5\%AD\%B8\%E7\%94\%9F\%E5\%BF\%83\%E7\%90\%86\%E5\%81\%A5\%E5 \%ВА\%B7\%Е7\%AF\%A9\%Е6\%AA\%A2\%Е9\%87\%8F\%Е8\%A1\%A8\%Е4\%B9\%8B\%Е7\%B7\%A8\%Е5\%88\% B6_\%E6\%9C\%80\%Е5\%BE\%8C\%E7\%89\%88.pdf.

Yakunina, E. S., Weigold, I. K, Weigold, A., Hercegovac, S., \& Elsayed, N. (2013). International students' personal and multicultural strengths: Reducing acculturative stress and promoting adjustment. Journal of Counseling \& Development, 91(2), 216-222. https://doi.org/10.1002/j.1556-6676.2013.00088.x

Ye J. (2005). Acculturative stress and use of the Internet among East Asian international students in the United States. Cyber Psychology and Behavior, 8, 154-61. https://doi.org/10.1089/cpb.2005.8.154

Ying, Y. W. (2005). Variation in acculturative stressors over time: A study of Taiwanese students in the United States. International Journal of Intercultural Relations, 29(1), 59-71. https://doi.org/10.1016/j.ijintrel.2005.04.003 